\title{
Dementia prevalence and incidence among the Indigenous and non-Indigenous populations of the Northern Territory
}

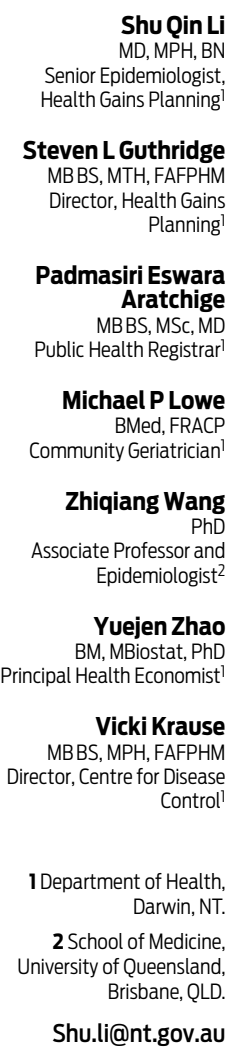

MJA 2014; 200: 465-469 doi: $10.5694 /$ mjal3.11052
W

ith a rapidly ageing population, dementia is commonly regarded as the leading health problem facing Australia in the 21st century. ${ }^{1}$ A report in 2007 estimated that the prevalence of dementia in Australians aged 65 years and over was about $6.5 \%$ and rising. ${ }^{2}$ Dementia is now the third leading cause of death in Australia, after heart disease and stroke. ${ }^{3}$ Dementia has an impact on every dimension of health and the health care system, with worldwide costs in 2010 estimated to have reached US $\$ 604$ billion. ${ }^{3}$

There have been few Australian studies of dementia prevalence, based on clinical diagnosis, and most information that is available has been collected for varying purposes and often based on meta-analysis of a mix of Australian and international information. $1,4,5$ Although useful, these studies have relied on relatively old data and the assumption that Australia has similar dementia prevalence and incidence to other countries, despite known differences in dementia risk factors. There remains a significant knowledge gap on the epidemiology of dementia in Australia generally and, more specifically, in the Australian Indigenous population.

A 2008 study reported that, based on clinical assessment, the prevalence of dementia in the Indigenous population of the Kimberley region of Western Australia was almost five times higher and the onset much earlier than the national average. ${ }^{6}$ An earlier study (1994) also found that the Indigenous people, aged 65 years and over, living in far North Queensland suffered from higher dementia prevalence $(20 \%){ }^{7}$ These results are consistent with the widely reported excess burden of disease in the Australian Indigenous population living in remote areas. 8,9 The higher prevalence was less evident in a

\section{Abstract \\ Objective: To estimate the prevalence and incidence of dementia in Northern Territory Indigenous and non-Indigenous populations.}

Design, setting and participants: Four data sources were used to identify clients with a diagnosis of dementia, from 1 January 2008 to 31 December 2011. The data sources included hospital admissions, aged care services, primary care and death registration. A capture-recapture method was used to estimate prevalence and incidence, including both diagnosed and unknown cases.

Main outcome measures: Prevalence and incidence of dementia among the NT Indigenous and non-Indigenous populations.

Results: In 2011, the estimated prevalence in the NT Indigenous population aged 45 years and over was 3.7 per 100, and 1.1 per 100 in the corresponding NT non-Indigenous population. The age-adjusted prevalence for the NT Indigenous population was 6.5 per 100, compared with the NT non-Indigenous prevalence of 2.6 per 100, which was similar to the national rate. The prevalence rate ratios of NT Indigenous to NT non-Indigenous men and women, respectively, were: 6.5 and 5.5 for the 45-64-years age group, 4.0 and 4.1 for those aged 65-74 years and 2.1 and 1.9 for those aged 75 years and over. The age-adjusted incidence among the NT Indigenous population aged 45 years and over (27.3 per 1000 person-years) was higher than that among the NT non-Indigenous population (10.7 per 1000 person-years).

Conclusion: The NT Indigenous population has a much higher prevalence and incidence of dementia and younger onset of disease compared with their nonIndigenous counterparts. The results highlight the urgent need for interventions to moderate the emerging impact of dementia in the Australian Indigenous population.

national study which used single data sources. ${ }^{10}$ The results in these three studies highlight the need for a broad population study to confirm prevalence and incidence of dementia in the Indigenous population. Importantly, dementia prevalence may be underestimated from a single data source even when the widely used diagnostic criteria are applied. ${ }^{11}$ Capture-recapture methods can be used to estimate the total number of cases in a population based on several incomplete sources. ${ }^{12}$

Dementia includes a range of conditions characterised by a progressive decline in cognitive, intellectual, memory and personality functions. ${ }^{5}$ About half of all dementia cases are diagnosed as Alzheimer disease, while other common types include vascular dementia, alcoholic dementia and unspecified dementia. Due to the silent onset and progressive nature of the disease, dementia patients may not be diagnosed for many years. ${ }^{13}$

The aims of this study were to estimate the prevalence and incidence of dementia in the Northern Territory Indigenous and non-Indigenous populations and to examine the demographic characteristics of diagnosed dementia cases.

\section{Methods}

\section{Data sources}

Four data sources were used to identify clients with a diagnosis of dementia, during the 4 -year period from 1 January 2008 to 31 December 2011. The NT Hospital Separations Dataset (HSD) contains comprehensive information on all admissions to the five NT public hospitals. The Primary Care Information System (PCIS) contains electronic clinical records for 
1 Age distribution of known dementia cases by Indigenous status, Northern Territory, 30 June 2011

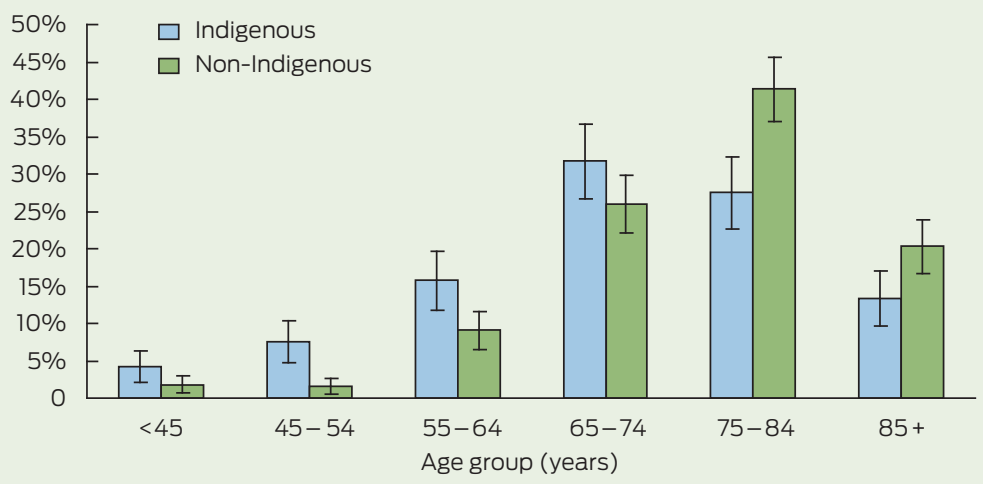

more than 30000 Indigenous clients attending 50 health centres in remote NT communities. This is nearly half the total NT Indigenous population. The third source was the NT Aged Care and Disability (ACD) database, which records assessment and ongoing specialised management of dementia clients. The fourth data source was death registration data from the NT Registry of Births, Deaths and Marriages (BDM). Australian Bureau of Statistics estimates of NT resident populations were used as denominators for rate calculations. ${ }^{14}$

The NT Department of Health uses a unique health identifier, known as the Hospital Registration Number (HRN), for all departmental services. Client demographic information, including $\mathrm{HRN}$, is contained within the central Client Master Index (CMI) database, which is the core of a data warehouse and links to all major client data systems. The HRN has been used in the warehouse for more than 20 years and is maintained with a program of continuing review and consolidation. It has been used in a number of previous linkage studies and has been reported as highly reliable.9,15 The HRN was used to link the three departmental datasets. Names, date of birth, sex and Indigenous status were used to match death registration records with CMI records. HRNs were then used to link death data with the other three datasets.

\section{Case definition}

Dementia cases, based on a recording of clinical diagnosis, were identified using the following definitions. HSD diagnosis fields are coded by trained clinical coders using the International
Classification of Disease, 10th revision (ICD-10). ${ }^{16}$ Cases were all clients with an admission during the study period and a principal or secondary diagnosis of dementia. Dementia cases in PCIS data were identified based on the International Classification of Primary Care, 2nd edition. ${ }^{17}$ Dementia cases were identified from ACD data based on the Aged Care Assessment Program Data Dictionary code list (codes 05000532). For BDM data, a key word search was used to identify dementia cases in the death registration dataset. Details of definitions and codes are provided in Appendix 1 (online at mja.com.au).

\section{Statistical analysis}

Diagnosed cases were identified from the multiple datasets and then, with capture-recapture, the degree of overlap between diagnosed cases in different datasets was used to estimate the number of missing (unknown) cases in the population. ${ }^{12}$ This approach involved a log-linear model with interaction terms to adjust for interdependence between data sources. The models tested were based on either three or four data sources. The inclusion of the fourth dataset (deaths) for prevalence estimates provided a marginal improvement and was retained for the final results. Dates of death were used to censor cases.

Prevalence and incidence were calculated based on all cases (diagnosed cases plus the estimate of unknown cases). Prevalence was estimated on a censoring date of 30 June 2011. Incidence was calculated based on new diagnoses recorded in any of the three data sources during the 2011 calendar year. Cases from previous years were excluded. Those individuals who died during 2011 were also excluded from the incidence model as they were considered unlikely to be newly diagnosed cases. Age-adjusted rates were calculated, using the direct method, for comparison with Australian rates.

\section{Ethics}

Ethics approval for the project was granted by the Human Research Ethics Committee of the NT Department of Health and Menzies School of Health Research (2012/1755).

\section{Results}

\section{Overview}

On 30 June 2011, there were 784 diagnosed dementia cases in the NT, identified from the four data sources. Of total diagnosed cases, 361 (46.0\%) were men and 423 (54.0\%) were women, while 311 (39.7\%) were Indigenous clients and 473 (60.3\%) were non-Indigenous clients. Indigenous clients were generally younger, with a median age of 72 years, compared with 79 years for non-Indigenous clients (Box 1).

Among diagnosed cases, the greatest proportion of both Indigenous (57.2\%) and non-Indigenous (45.2\%) clients had an unspecified diagnosis of dementia. Alzheimer disease was documented for $15.1 \%$ of Indigenous and $22.6 \%$ of non-Indigenous clients, while vascular dementia was documented for $19.3 \%$ of Indigenous and $22.4 \%$ of non-Indigenous clients. Alcoholrelated dementia was recorded for $7.4 \%$ of Indigenous and $8.5 \%$ of non-Indigenous clients. Details of dementia types are provided in Appendix 2 (online at mja.com.au).

\section{Prevalence}

The results of the log-linear model for prevalence estimates, using four data sources, are presented in Box 2. There were estimated to be 249 unknown dementia cases at 30 June 2011, with 119 cases in the Indigenous and 130 in the non-Indigenous population.

The estimated prevalence for dementia in the total NT population aged 45 years and over was 1.6 per 100 population, with 3.7 per 100 in the Indigenous population and 1.1 per 100 in the nonIndigenous population. After adjustment to the national age distribution, the age-adjusted prevalence for the NT total population aged 45 years and 
2 Prevalence of dementia by age group, sex and Indigenous status, Northern Territory, 2011

\begin{tabular}{|c|c|c|c|c|c|}
\hline Age, sex and Indigenous status & $\begin{array}{l}\text { Actual cases in } \\
\text { datasets }\end{array}$ & $\begin{array}{c}\text { Estimated } \\
\text { missing cases }\end{array}$ & Population & $\begin{array}{l}\text { Prevalence (per } \\
100 \text { population) }\end{array}$ & $95 \% \mathrm{Cl}$ \\
\hline \multicolumn{6}{|l|}{ Indigenous } \\
\hline \multicolumn{6}{|l|}{ Men } \\
\hline 45-64 years & 47 & 9 & 4176 & 1.3 & $1.1-1.7$ \\
\hline $65-74$ years & 40 & 13 & 663 & 8.0 & $5.9-10.1$ \\
\hline $75+$ years & 38 & 25 & 272 & 23.2 & $18.1-28.2$ \\
\hline Age-adjusted prevalence in men aged $45+$ years & 125 & 47 & 511 & 6.1 & $5.1-7.2$ \\
\hline \multicolumn{6}{|l|}{ Women } \\
\hline 45-64 years & 39 & 14 & 5037 & 1.1 & $0.8-1.3$ \\
\hline $65-74$ years & 60 & 20 & 1056 & 7.6 & $6.0-9.2$ \\
\hline $75+$ years & 87 & 38 & 442 & 28.3 & $24.1-32.5$ \\
\hline Age-adjusted prevalence in women aged $45+$ years & 186 & 72 & 6535 & 6.7 & $5.8-7.0$ \\
\hline $\begin{array}{l}\text { Age-adjusted prevalence in Indigenous population } \\
\text { aged } 45+\text { years }\end{array}$ & 311 & 119 & 11646 & 6.5 & $5.8-6.8$ \\
\hline \multicolumn{6}{|l|}{ Non-Indigenous } \\
\hline \multicolumn{6}{|l|}{ Men } \\
\hline 45-64 years & 36 & 12 & 23426 & 0.2 & $0.1-0.3$ \\
\hline $65-74$ years & 71 & 17 & 4403 & 2.0 & $1.6-2.4$ \\
\hline $75+$ years & 129 & 34 & 1482 & 11.0 & $9.4-12.6$ \\
\hline Age-adjusted prevalence in men aged $45+$ years & 236 & 63 & 29311 & 2.3 & $2.0-2.6$ \\
\hline \multicolumn{6}{|l|}{ Women } \\
\hline 45-64 years & 19 & 13 & 19850 & 0.2 & $0.1-0.3$ \\
\hline $65-74$ years & 37 & 18 & 2942 & 1.9 & $1.4-2.4$ \\
\hline $75+$ years & 181 & 36 & 1463 & 14.8 & $13.0-16.7$ \\
\hline Age-adjusted prevalence in women aged $45+$ years & 237 & 67 & 24255 & 2.9 & $2.5-3.2$ \\
\hline $\begin{array}{l}\text { Age-adjusted prevalence in non-Indigenous population } \\
\text { aged } 45+\text { years }\end{array}$ & 473 & 130 & 53566 & 2.6 & $2.3-2.8$ \\
\hline $\begin{array}{l}\text { Age-adjusted prevalence in total population aged } 45+ \\
\text { years }\end{array}$ & 784 & 249 & 65212 & 3.3 & $3.1-3.5$ \\
\hline
\end{tabular}

over was 3.3 per 100 population (Box 2). The age-adjusted prevalence in the NT Indigenous population was 6.5 per 100, while the age-adjusted prevalence in the NT non-Indigenous population was 2.6 per 100 , which was similar to the national prevalence (2.4 per 100 population). ${ }^{5}$ The age-adjusted prevalence for women was higher in both NT Indigenous and NT non-Indigenous populations. The age-specific prevalence rate ratios of NT Indigenous to NT non-Indigenous clients were: 6.5 for men and 5.5 for women aged 45-64 years, 4.0 for men and 4.1 for women aged 65-74 years; 2.1 for men and 1.9 for women aged 75 years and over.

\section{Incidence}

The results of the log-linear model for incidence estimates for populations aged 45 years and over, using three data sources, are presented in Box 3. In 2011, there were 205 diagnosed incident cases while the statistical model estimated an additional 241 unknown cases. The age-adjusted incidence for the total NT population was 13.9 cases per 1000 person-years. The age-adjusted incidence in the NT Indigenous population was much higher at 27.3 cases per 1000 personyears than in the NT non-Indigenous population with 10.7 cases per 1000 person-years. The NT non-Indigenous rate was slightly higher than the reported national rate $(9.2$ per 1000 person-years). ${ }^{18}$

The incidence among men was higher than that among women in both NT Indigenous and non-Indigenous populations for all age groups except non-Indigenous people aged 65-74 years. Incidence rate ratios of NT Indigenous to non-Indigenous were higher for the younger age groups (4564 years) in both men and women.

\section{Discussion}

This study found that the prevalence of dementia for the total NT population aged 45 years and above was higher than national estimates. ${ }^{5} \mathrm{NT}$ has the fastest growing older population of all Australian states, and the prevalence of dementia in NT will continue to increase. ${ }^{14}$ The rapidly increasing demands on the aged care sector, including for dementia services, have significant implications for social, economic and health care planning in the NT.

Consistent with two previous studies, ${ }^{6,7}$ the prevalence of dementia among NT Indigenous people aged 45 years and over was much higher than national estimates. The difference in rate ratios between age groups highlights the earlier onset of dementia among the Indigenous population, which is also consistent with the previous study among the WA Indigenous population in the Kimberley region. ${ }^{6}$ Our study also found markedly higher incidence of dementia in the NT Indigenous population compared with the national estimates. ${ }^{18}$ The finding of early onset and high incidence of dementia suggests that the burden of dementia among the NT Indigenous population will continue to increase, along with both the increase in number of older Indigenous people and improved life expectancy. 
3 Incidence of dementia by age group, sex and Indigenous status, Northern Territory, 2011

\begin{tabular}{|c|c|c|c|c|c|}
\hline Age groups & $\begin{array}{c}\text { Actual cases in } \\
\text { datasets }\end{array}$ & $\begin{array}{c}\text { Estimated } \\
\text { missing cases }\end{array}$ & Population & $\begin{array}{c}\text { Incidence (per } 1000 \\
\text { person-years) }\end{array}$ & $95 \% \mathrm{Cl}$ \\
\hline \multicolumn{6}{|l|}{ Indigenous } \\
\hline \multicolumn{6}{|l|}{ Men } \\
\hline $45-64$ years & 9 & 10 & 4176 & 4.5 & $2.5-6.6$ \\
\hline $65-74$ years & 12 & 18 & 663 & 45.2 & $29.4-61.1$ \\
\hline $75+$ years & 11 & 29 & 272 & 147.1 & 105.0-189.1 \\
\hline Age-adjusted incidence in men aged $45+$ years & 32 & 57 & 511 & 35.3 & $27.0-43.5$ \\
\hline \multicolumn{6}{|l|}{ Women } \\
\hline 45-64 years & 9 & 7 & 5037 & 3.2 & $1.6-4.7$ \\
\hline $65-74$ years & 13 & 12 & 1056 & 23.7 & $14.5-32.8$ \\
\hline $75+$ years & 24 & 19 & 442 & 97.3 & $69.7-124.9$ \\
\hline Age-adjusted incidence in women aged $45+$ years & 46 & 38 & 6535 & 22.3 & $17.0-27.5$ \\
\hline $\begin{array}{l}\text { Age-adjusted incidence in Indigenous population } \\
\text { aged } 45+\text { years }\end{array}$ & 78 & 95 & 11646 & 27.3 & $22.8-31.8$ \\
\hline \multicolumn{6}{|l|}{ Non-Indigenous } \\
\hline \multicolumn{6}{|l|}{ Men } \\
\hline $45-64$ years & 11 & 16 & 23426 & 1.2 & $0.7-1.6$ \\
\hline $65-74$ years & 23 & 28 & 4403 & 11.6 & $8.4-14.7$ \\
\hline $75+$ years & 34 & 44 & 1482 & 52.6 & $41.3-64.0$ \\
\hline Age-adjusted incidence in men aged $45+$ years & 68 & 88 & 29311 & 11.4 & $9.4-13.5$ \\
\hline \multicolumn{6}{|l|}{ Women } \\
\hline $45-64$ years & 7 & 10 & 19850 & 0.9 & $0.4-1.3$ \\
\hline $65-74$ years & 17 & 19 & 2942 & 12.2 & $8.3-16.2$ \\
\hline $75+$ years & 35 & 29 & 1463 & 43.7 & $33.3-54.2$ \\
\hline Age-adjusted incidence in women aged $45+$ years & 59 & 58 & 24255 & 9.9 & $8.0-11.9$ \\
\hline $\begin{array}{l}\text { Age-adjusted incidence in non-Indigenous } \\
\text { population aged } 45+\text { years }\end{array}$ & 127 & 146 & 53566 & 10.7 & $9.3-12.1$ \\
\hline $\begin{array}{l}\text { Age-adjusted incidence in total population aged } 45+ \\
\text { years }\end{array}$ & 205 & 241 & 65212 & 13.9 & $12.4-15.3$ \\
\hline
\end{tabular}

The methods used in the study indicated that there remain many cases of dementia which have not yet been detected. Undetected cases in the Indigenous population were overrepresented for the population, with $47.8 \%$ of the estimate of unknown cases being Indigenous, whereas $30 \%$ of total NT population are Indigenous. This differential is consistent with lower access to or usage of services in remote areas ${ }^{19}$ and the language and cultural complexities of appropriate services for Indigenous populations. While the prevalence estimates provide a broad measure for planning appropriate services, the incidence estimate raises even greater concern. More than half of estimated dementia cases were not identified in a timely manner, a finding that supports the need for measures to attain more timely diagnosis and reduce premature death. Such measures include improved support for health care providers to recognise dementia, to be aware of those groups at higher risk of dementia and to provide appropriate support for referral. Whether a population-based screening program may be warranted to improve identification of cases requires further consideration. 20

The high prevalence and incidence of dementia among the NT Indigenous population were consistent with the high prevalence of well known risk factors for dementia such as stroke, epilepsy, brain injury, smoking and alcohol-related health problems. $8,9,21$ It is increasingly recognised that early life events and social and biological factors may interact to influence the ageing process throughout the lifespan. ${ }^{22}$ Environmental factors can also affect an individual's physical functioning and ability to participate in society. ${ }^{22,23}$ Although there is currently no cure for dementia, many risk factors are modifiable by public health measures. Effective blood pressure control and strategies to reduce smoking and alcohol misuse are important in managing dementia risk and future burden. The high proportion of unspecified dementia has implications for both service planning and case management. More complete dementia diagnosis in aged care registration, hospital inpatients and primary care services in remote Indigenous communities is urgently needed.

Our study has a number of limitations. First, it is possible that the linkage of the same individuals in different datasets was incomplete. This would have the effect of overestimating prevalence and incidence. However, the unique patient identifier within NT health data has previously been shown to be reliable, and a substantial majority of individuals within the samples were linked across data sources. A second limitation is that capture-recapture methods assume a closed population. The older non-Indigenous population, in particular, may move either into or out of the NT at a time of declining health or retirement. The similarity of results with the national estimate suggests that the effect of interstate migration may not be substantial. While the NT Indigenous population is highly mobile within the NT, interstate migration is minimal. ${ }^{24} \mathrm{~A}$ third limitation is that the study relied on recording of a clinical diagnosis in the 
electronic data systems. Case notes and clinical reviews were not available to validate diagnoses. A final limitation is that only 4 years' data were available for the study. If information had been available for a longer period, some additional cases may have been identified and apparent incident cases may have been recognised as having had an earlier onset. Using four different data sources reduced the likelihood of our having missed the index episode. Future estimates, based on these data sources, will benefit from the availability of additional years of data.

There is growing recognition that dementia is a major global health problem of the 21st century. This study demonstrates the opportunity to use existing administrative data to inform a significant knowledge gap in population-level data. In this case, the results highlight the specific and emerging needs in the NT Indigenous population. More generally in Australia, large-scale population studies are warranted in order to better understand the burden, regional variation and social costs of dementing conditions.

Acknowledgements: Zhiqiang Wang was supported by a National Health and Medical Research Council Fellowship (APP1042343)

Competing interests: No relevant disclosures.

Received 13 Aug 2013, accepted 8 Dec 2013.

1 Deloitte Access Economics. Dementia across Australia: 2011-2050. Canberra: Alzheimer's Australia, 2011.

2 Australian Institute of Health and Welfare. Older Australia at a glance: 4th ed. Canberra: AlHW, 2008. (AlHW Cat. No. AGE 52.)

3 Alzheimer's Australia. Summary of dementia statistics in Australia. http:// www.fightdementia.org.au/understandingdementia/statistics.aspx (accessed May 2013).

4 Access Economics. Dementia estimates and projections: Australian states and territories. Canberra: Alzheimer's Australia, 2005.

5 Australian Institute of Health and Welfare. Dementia in Australia: national data analysis and development. Canberra: AlHW, 2006. (AlHW Cat. No. AGE 53.)

6 Smith K, Flicker L, Lautenschlager NT, et al. High prevalence of dementia and cognitive impairment in Indigenous Australians. Neurology 2008; 71: 1470-1473.

7 Zann S. Identification of support, education and training needs of rural/remote health care service providers involved in dementia care: Rural Health Support, Education and Training (RHSET) final report. Townsville, Qld: Aboriginal and Islander Health Program, Northern Regional Health Authority, c1994.

8 Zhao Y, You J, Guthridge S. Burden of disease and injury in the Northern Territory, 1999-2003. Darwin: Department of Health and Families, 2009.

9 You J, Condon JR, Zhao Y, Guthridge S. Incidence and survival after acute myocardial infarction in Indigenous and non-Indigenous people in the
Northern Territory, 1992-2004. Med J Aust 2009; 190: 298-302.

10 Cotter PR, Condon JR, Barnes T, et al. Do Indigenous Australians age prematurely? The implications of life expectancy and health conditions of older Indigenous people for health and aged care policy. Aust Health Rev 2012; 36: 68-74. http://dx.doi.org/10.1071/AH11996 (accessed Oct 2013).

11 Prince M, Acosta D, Ferri CP, et al. Dementia incidence and mortality in middle-income countries, and associations with indicators of cognitive reserve: a 10/66 Dementia Research Group population-based cohort study. Lancet 2012; 380: 50-58.

12 Chao A, Tsay PK, Lin SH, et al. The applications of capture-recapture models to epidemiological data. Stat Med 2001; 20: 3123-3157.

13 Bradford A, Kunik ME, Schulz P, et al. Missed and delayed diagnosis of dementia in primary care: prevalence and contributing factors. Alzheimer Dis Assoc Disord 2009; 23: 306-314.

14 Australian Bureau of Statistics. Australian demographic statistics. Canberra: ABS, 2010. (ABS Cat. No. 3101.0.)

15 Zhao Y, Condon JR, Li SQ, et al. Indigenous patient migration patterns after hospitalisation and the potential impacts on mortality estimates. AJRS 2013; 19: 321-341.

16 National Centre for Classification in Health. The international statistical classification of disease and related health problems, 10th revision, Australian modification (ICD-10-AM). Sydney: NCCH, 2004.
17 WONCA International Classification Committee. International classification of primary care. Revised 2nded. Oxford: Oxford University Press, 2005.

18 Access Economics. Keeping dementia front of mind: incidence and prevalence 2009-2050. Canberra: Alzheimer's Australia, 2009.

19 Byron P, Zhao Y, Guthridge S, et al. Medicare and Pharmaceutical Benefits Scheme usage patterns in the Northern Territory 1993/94 to 2003/04. Darwin, NT: NT Department of Health and Community Services, 2005.

20 Brayne C, Fox C, Boustani M. There is no evidence base for proposed dementia screening BMJ 2012; 345: e8588.

21 Li SQ, Pircher SLM, Guthridge SL. Trends in alcohol-attributable hospitalisation in the Northern Territory, 1998-99 to 2008-09. Med J Aust 2012; 197: 341-344.

22 Smith K, Flicker L, Dwyer A, et al. Factors associated with dementia in Aboriginal Australians. Aust N Z J Psychiatry 2010; 44 : 888-893.

23 Beland F, Zunzunegui MV, Alvarado B, et al Trajectories of cognitive decline and social relations. J Gerontol B Psychol Sci Soc Sci 2005; 60: P320-P330.

24 Condon JR, Barnes T, Cunningham J, Smith L. Demographic characteristics and trends of the Northern Territory Indigenous population, 1966 to 2001. Occasional paper. Darwin, NT: Cooperative Research Centre for Aboriginal Health, 2004. 